\title{
Changes in population susceptibility to heat and cold over time: assessing adaptation to climate change
}

\author{
Katherine Arbuthnott ${ }^{1,2^{*}}$, Shakoor Hajat ${ }^{1}$, Clare Heaviside ${ }^{1,2}$ and Sotiris Vardoulakis ${ }^{1,2}$
}

From The 11th International Conference on Urban Health

Manchester, UK. 6 March 2014

\begin{abstract}
Background: In the context of a warming climate and increasing urbanisation (with the associated urban heat island effect), interest in understanding temperature related health effects is growing. Previous reviews have examined how the temperature-mortality relationship varies by geographical location. There have been no reviews examining the empirical evidence for changes in population susceptibility to the effects of heat and/or cold over time. The objective of this paper is to review studies which have specifically examined variations in temperature related mortality risks over the $20^{\text {th }}$ and $21^{\text {st }}$ centuries and determine whether population adaptation to heat and/or cold has occurred.
\end{abstract}

Methods: We searched five electronic databases combining search terms for three main concepts: temperature, health outcomes and changes in vulnerability or adaptation. Studies included were those which quantified the risk of heat related mortality with changing ambient temperature in a specific location over time, or those which compared mortality outcomes between two different extreme temperature events (heatwaves) in one location.

Results: The electronic searches returned 9183 titles and abstracts, of which eleven studies examining the effects of ambient temperature over time were included and six studies comparing the effect of different heatwaves at discrete time points were included. Of the eleven papers that quantified the risk of, or absolute heat related mortality over time, ten found a decrease in susceptibility over time of which five found the decrease to be significant. The magnitude of the decrease varied by location. Only two studies attempted to quantitatively attribute changes in susceptibility to specific adaptive measures and found no significant association between the risk of heat related mortality and air conditioning prevalence within or between cities over time. Four of the six papers examining effects of heatwaves found a decrease in expected mortality in later years. Five studies examined the risk of cold. In contrast to the changes in heat related mortality observed, only one found a significant decrease in cold related mortality in later time periods.

Conclusions: There is evidence that across a number of different settings, population susceptibility to heat and heatwaves has been decreasing. These changes in heat related susceptibility have important implications for health impact assessments of future heat related risk. A similar decrease in cold related mortality was not shown. Adaptation to heat has implications for future planning, particularly in urban areas, with anticipated increases in temperature due to climate change.

Keywords: Climate change, Adaptation, Temperature, Heat, Cold, Heatwave, Mortality, Health

\footnotetext{
* Correspondence: Katherine.arbuthnott@lshtm.ac.uk

${ }^{1}$ Department of Social and Environmental Health Research, London School

of Hygiene \& Tropical Medicine, London, WC1H 9SH, UK

${ }^{2}$ Environmental Change Department, Centre for Radiation, Chemical and

Environmental Hazards, Public Health England, Didcot OX11 ORQ, UK
} 


\section{Background}

The global climate is projected to warm although to what extent depends on future greenhouse gas emissions and socioeconomic and land use changes. Global surface temperatures are likely to warm by between $0.3{ }^{\circ} \mathrm{C}$ and $4.8{ }^{\circ} \mathrm{C}$ by the end of this century relative to the end of the last, depending on modelling choices which reflect differences in the amount of anthropogenic forcing in different scenarios [1]. It is anticipated that there will be increasing variability in future temperatures and extreme weather events over most geographical regions [1-4]. For example, heatwaves are likely to increase in frequency and severity and this, combined with projected demographic changes, will lead to an increase in population exposure to extreme events $[5,6]$. However, the same locations may still experience (extreme) low temperatures. These are important considerations for public health, as both heat and cold exposure lead to increased risk of mortality [7-21].

Adequate public health responses to temperature related effects of climate change require a sound risk management process, informed by the use and synthesis of relevant evidence. A framework for such a public health approach for climate change adaptation is outlined by Hess et al. [22]. In considering the future impact of temperature on health, knowledge about past and current risks to health from changes in ambient temperature is essential: it informs the baselines used for future risk assessments upon which management strategies may be based. Changes in temperature related health outcomes over time could give valuable insight into whether populations have adapted to hot and/or cold temperatures in more recent times. Understanding what has caused changes in susceptibility to temperature related mortality can help inform current public health policy and protection of vulnerable communities. Alternatively, if temperature related mortality remains unchanged this gives further weight to the need for specific planned adaptive strategies to address the health risks of future climate change. For the purpose of this review, adaptation and acclimatisation have been defined as in Fig. 1 below, with the definition of adaptation based upon that of the Intergovernmental Panel on Climate Change [23]. However, a distinction between evidence of decreasing susceptibility to heat and cold and evidence that adaptation or acclimatisation have occurred should be made. For example, a decrease in temperature related mortality may have arisen through general improvements in health or social care rather than specific planned adaptations to the effects of heat or cold: to attribute decreasing heat or cold related mortality solely to planned adaptive measures would be misleading.

Epidemiological evidence for the effect of temperature on health outcomes is typically based on observational studies. The relative risk of mortality per unit change in temperature (e.g. per degrees Celsius $\left({ }^{\circ} \mathrm{C}\right)$ ) is generally estimated using a time series or case-crossover approach. This is usually denoted by 'U', 'V' or 'J' type curves, with adverse health effects appearing below or above a given range of temperatures [11]. Where a threshold temperature is set, above or below which health effects occur (and can be estimated using a log-linear or non-linear approach), this point is often referred to as the Minimum Mortality Temperature (MMT). The effect of individual heatwaves is often estimated using episode analysis, where observed numbers of deaths during the heatwave period are compared to expected deaths estimated using an appropriate baseline.

A number of epidemiological studies [24-26] have examined how temperature-mortality relationships vary by geographical location. The geographical variation in this relationship is also the subject of a review by Hajat and Kosatsky [27], who explored possible explanations for the differences in temperature related susceptibility between countries. In a random-effects meta-regression of studies, the relative risk of heat related mortality was found to be strongly related to heat thresholds. Heat thresholds (and RR of heat-related mortality) were higher in countries closer to the equator (with higher summertime mean temperatures). It was proposed that the higher thresholds seen in countries closer to the equator, may indicate some level of population adaptation to heat. The risk of heat-related mortality was also found to increase with increasing urban density, decreasing city level GDP and increasing age of the population.

No review, however, has examined how or whether temperature-related mortality varies over time in one location. This paper seeks to address this gap in knowledge. Specifically we review the evidence for changing population susceptibility (in terms of mortality) to ambient heat and cold and heatwaves or cold snaps over different time points over the last century and more recently. Understanding changing temperature-related mortality, the time scales over which this has occurred, and its possible causes could make important contributions to managing future risk. We discuss the extent to which changes in susceptibility are attributed to planned adaptive measures within the selected studies and consider how this evidence could be used in assessments of future temperature related health impacts. Both heat and cold related mortality are reviewed, as in many parts of the world studies suggest cold related mortality currently has and will continue to have a substantial contribution to temperature related mortality, even under warming projections $[28,29]$.

We review both changes in mortality in response to general temperature increases or decreases and to extreme weather events, such as heatwaves and cold snaps. Extreme events are included since the specific adaptive measures 


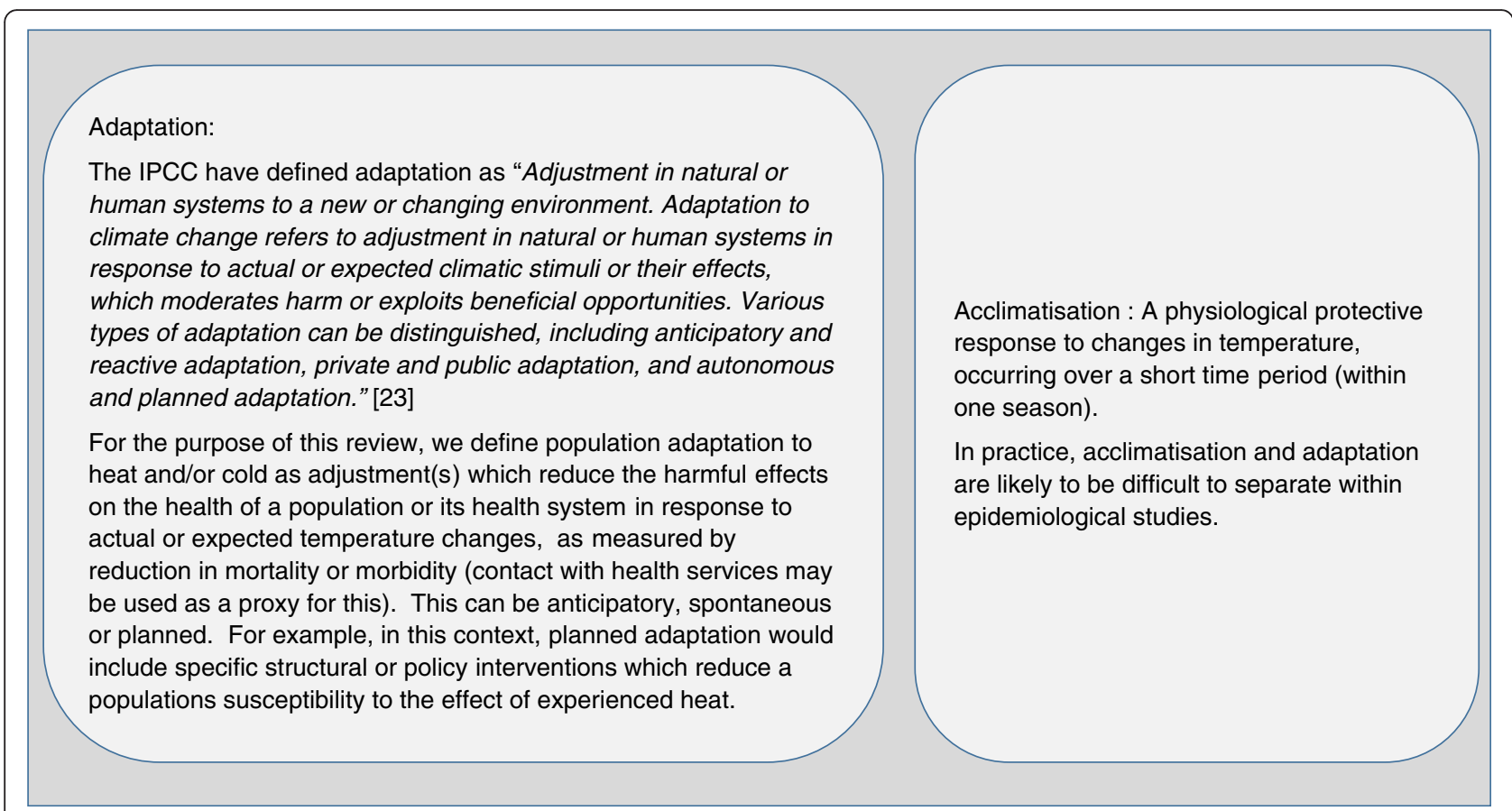

Fig. 1 Definition of Adaptation (based on the Intergovernmental Panel on Climate Change (IPCC) definition [23]) and Acclimatisation

and policies relating to these may differ to those for general temperature effects. For example, there are many specific measures, such as heat health warning systems (HHWS) that are only fully activated during an extreme event [30, 31]. Political will to react to extreme events, such as the 2003 heatwave (commonly stated as the trigger for many European countries' HHWS) may be greater [32], as although considered low probability they have an immediate and high impact compared to slowly changing environmental risk.

Only the direct effects of ambient temperature on health (all cause and cause specific mortality - for example mortality due to cardiac or respiratory disease) are considered in this review. A review of individual and specific adaptive measures (e.g. the effectiveness of electric fans, or heat health warning systems) is beyond the scope of this paper and has, in part, been undertaken in previous works [33-35].

\section{Methods}

All populations, analysed/aggregated at either city, regional or national level, were included in this review. We included observational studies (time series, case-crossover or period analysis design) which:

- quantified the risk of health related events with changing ambient temperature in one location over a given time period (not limited); or

- compared outcomes between two different discrete extreme temperature events ( $>1$ day, for example, usually defined by the context specific definition of a heatwave or cold spell) in one location.

Where studies compared the effect of temperature extremes but by individual days (e.g. risk at the $98^{\text {th }}$ percentile of temperatures compared with average temperature but as part of a heatwave) these were categorised as the first type of study - assessing the effect of ambient increased temperature on health.

The primary outcome assessed was mortality (all cause or by type), as estimations of this are not sensitive to changes in organisation of care (whereas, hospital admission rates for example, may change over time, not as a function of morbidity but related to changing expectations or access to care). Studies which only examined deaths coded as due to heat or temperature disturbances (e.g. heatstroke, hypo/hyper-thermia) were excluded as these deaths are comparatively rare, the coding of such death may vary and they may also be associated with occupational or working conditions unrelated to ambient temperature (e.g. heat stroke may occur in military recruits in training etc.). Studies were excluded if there were no quantitative results available that compared mortality (risk or rates or attributable burden) over time.

Five electronic databases were searched (Ovid MEDLINE, Ovid EMBASE, CINAHL, Psych- info and Global Health) using three main concepts: temperature, health outcomes and changes in vulnerability or adaptations. Search terms were combined using the appropriate Boolean operator terms and limited to English and to 
humans. Further articles were identified through snowballing of references and hand searching of relevant journals not indexed in the databases (e.g. Nature Climate Change).

Data from studies was extracted on location and duration of the study, exposures studied, health outcome measures, methods used for estimating the effect and methods used to assess changes in mortality at the time points recorded. Where available, subgroup analysis was also recorded (e.g. by age category or by cause of death). Contextual information, for example whether protective measures had been introduced during the study time period, was recorded even if the description of these was qualitative rather than quantitative.

Due to the heterogeneity of approaches to defining and assessing changes in temperature related mortality risk (for example, changes in relative risk (RR) or attributable mortality burdens over time) a meta-analysis was not deemed appropriate. Where complete results from more than one statistical model were presented, those that were reported in full or stated to be the main model by the authors are included. When results from more than one model were given, those judged to have the best control for confounders or best fit to data were chosen. Where estimates were made over a period of time the mid-point of this time period was used when representing the information.

\section{Results}

Eleven studies met the inclusion criteria examining changes in susceptibility to heat and cold over time and six studies of heatwaves met the inclusion criteria.

\section{Changes in vulnerability to ambient heat and cold over time (non- heatwaves) \\ Types of study and methods used}

Eleven studies [36-46] were identified that had quantitatively analysed changes in the effects of either ambient heat, cold or both on mortality over time. The key information about study populations, outcomes and methods is summarised in Table 1. The majority of studies used data from the US or Europe. The time periods studied ranged from 18 to 150 years. Eight studies focused only on urban populations [36-40, 43, 46], eight analysed all age groups of which four reported trends in time also by age category [36-39] and two papers only analysed older age groups $[43,45]$. Five studies examined the effects of both high and low temperatures [39, 41-44], whilst all others only examined the effect of heat. Ten papers examined all-cause mortality, of which three also analysed trends in heat related cardiovascular and/or respiratory deaths $[37,38,44]$ and one paper only analysed cardiovascular mortality [43].
A variety of health outcome measures were used within the time series studies to analyse the effect of temperature on health and how this varied with time (see Tables 1 and 2 ). Results were either presented as the RR of mortality per $1{ }^{\circ} \mathrm{C}$ (or $10^{\circ} \mathrm{F}$ ) increase in temperature [36, 38, 39, 43, 44], the RR of mortality at one temperature compared to another (e.g. $29^{\circ} \mathrm{C}$ vs $22{ }^{\circ} \mathrm{C}$ ) [36] or the $98^{\text {th }}$ centile vs average temperature [39] or as the (average) annual number of excess heat or cold related deaths as a proportion of the population $[45,46]$ or of deaths [37]. The most common approach used to examine changes in susceptibility over time was the comparison of $R R$ or excess temperature related deaths from the models on an annual or decadal basis or between two defined time points. The extent to which trends could be identified or were quantified varied, with some studies also analysing year or decade as a modifying factor in the relationship or using regression to examine the effect of time on heat/cold related health outcomes [36, 45].

Where the time series models used a linear-threshold approach to estimate the effect of temperature on mortality, different decisions were taken regarding setting the threshold above or below which temperature effects were estimated. In some cases $[42,45]$ a change in threshold or MMT was used to support evidence for or against changes in susceptibility (i.e. an increase in threshold represents a decrease in susceptibility to heat). Even if not specifically analysed, a change in threshold is important as it relates to the slope of the regression line. One paper fixed the threshold [44] across the entire analysis period but noted that it increased in later years and two papers [42, 46, 47] allowed the threshold to vary between decades. These approaches are commented on further in the discussion section.

The amount of control for time varying factors within the epidemiological models varied. For example, only one paper specifically reported including air pollution control in the main model [44] and this was only for the last part of the century due to limited data availability (see Table 1). One study [37] reported control for air pollution as part of their sensitivity analysis and supplementary materials. In those studies reporting cold effects over time, control for influenza varied (see section on varation in effect by study design and metrics used).

\section{Temporal changes in susceptibility to ambient heat}

The effect of increased temperature on mortality was examined in eleven studies [36-46]. Of these, ten found evidence of some decrease in susceptibility to heat (see Table 1). Seven reported a measure of statistical significance - either a test for trend or included confidence intervals for estimates at two discrete time points. Of these seven, five found the decrease over time or between two time periods to be statistically significant at the $5 \%$ 


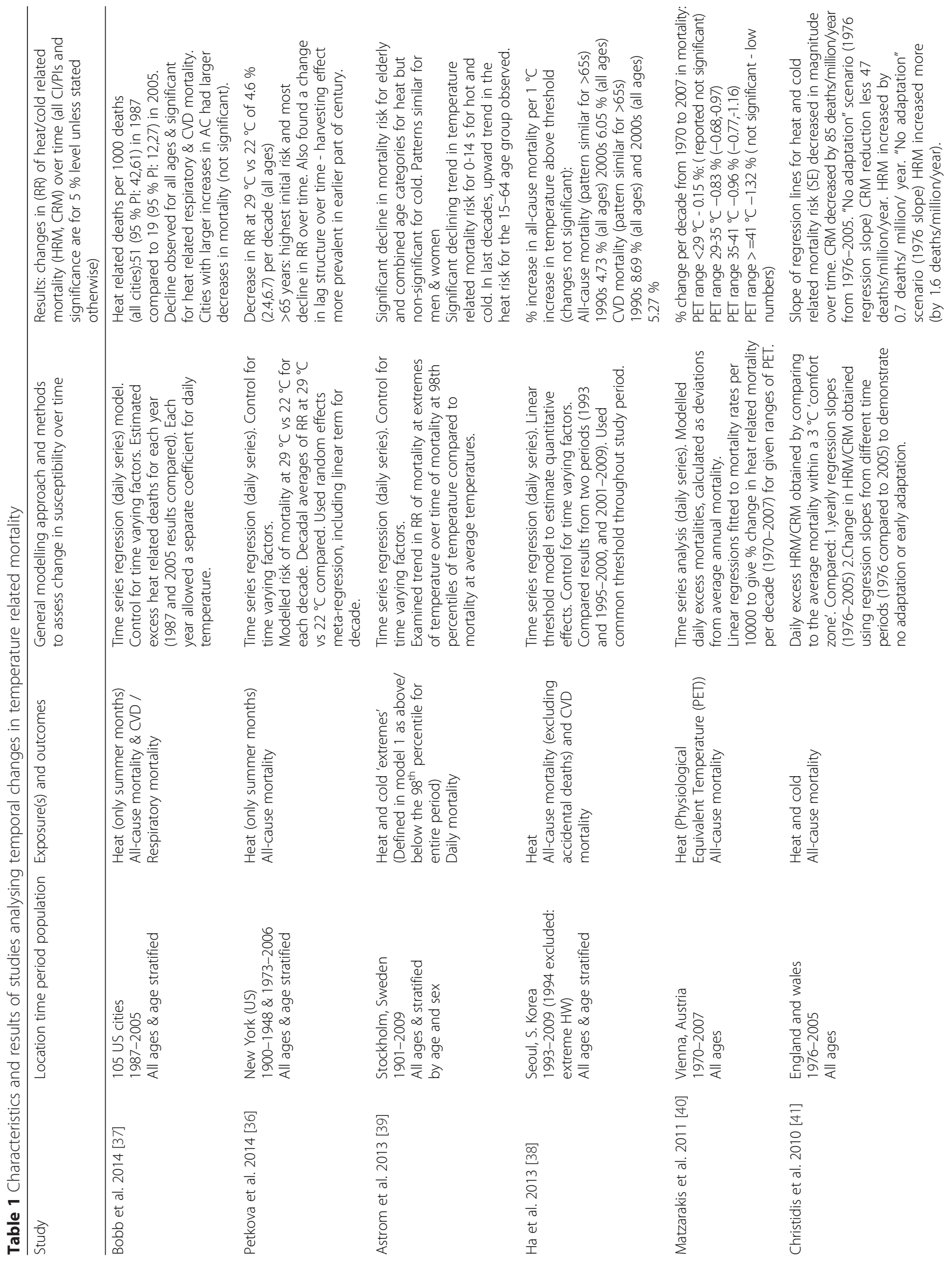




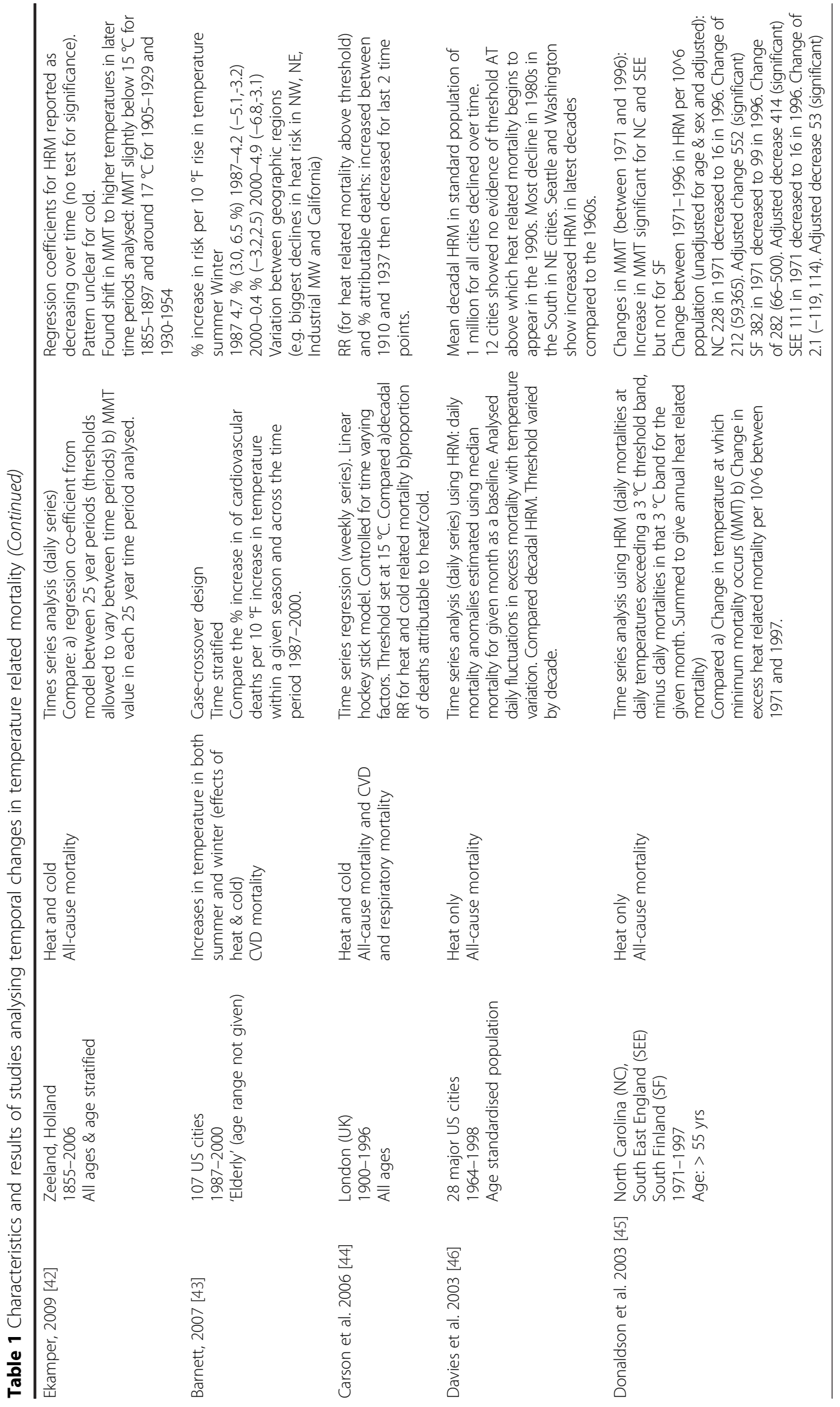




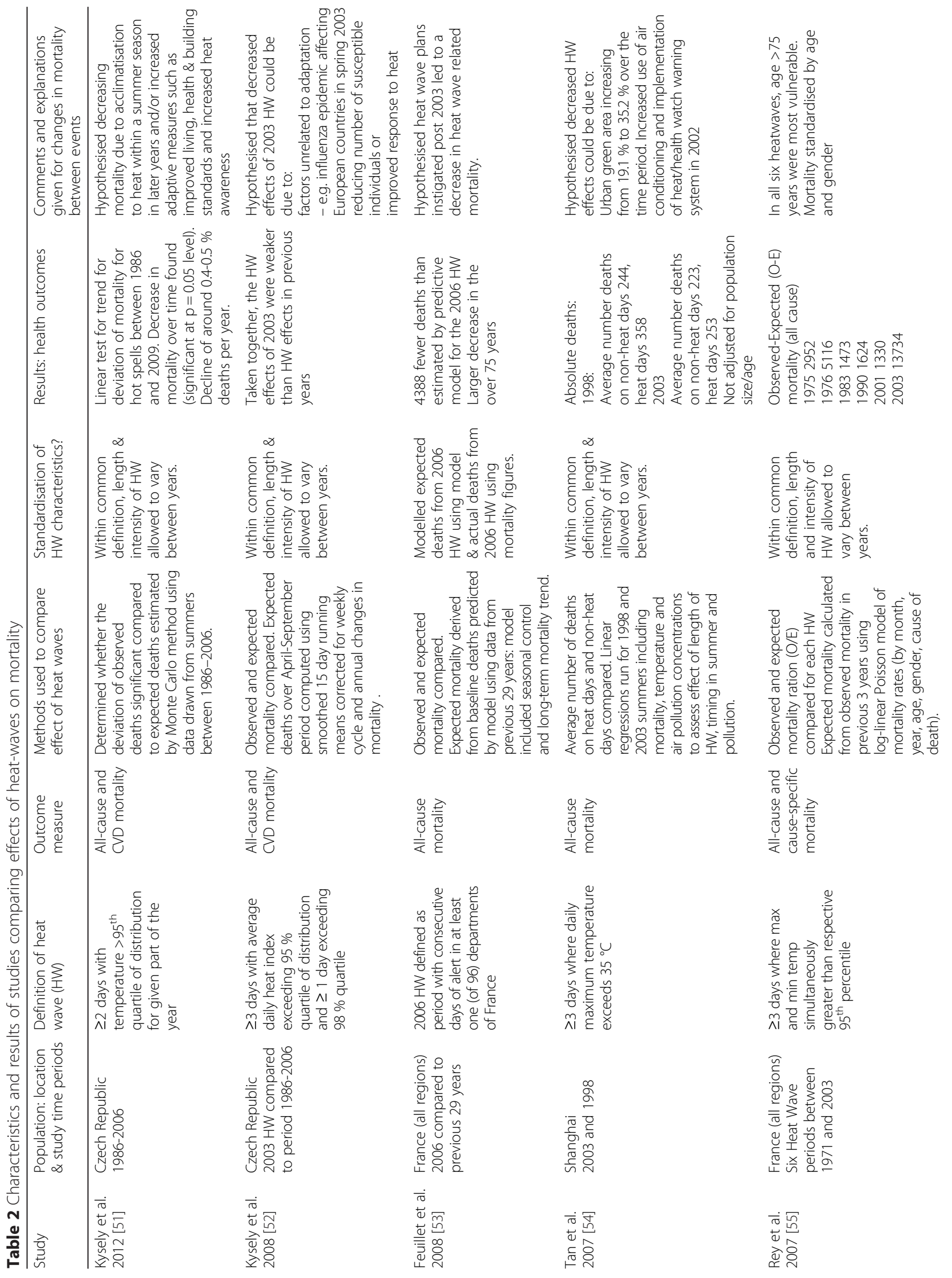




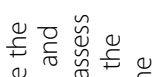

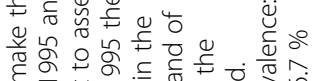

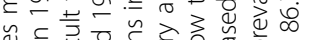

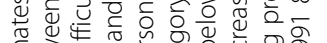

है

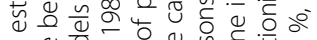

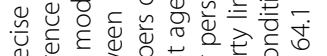

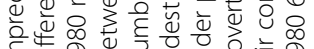

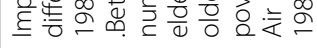

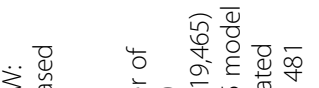

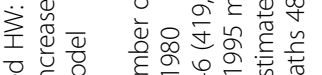

要.

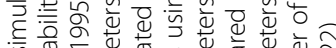

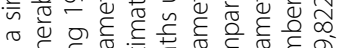

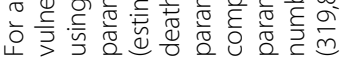

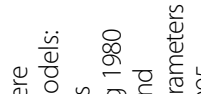

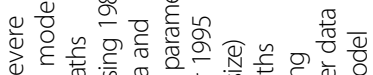

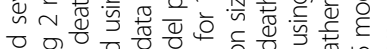

嵌.

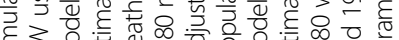

吝

高

을

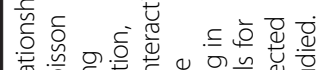

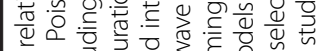

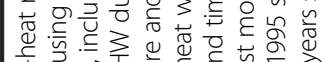

1

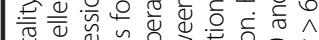

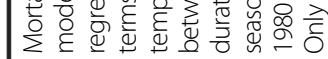

离

学

날

$\cup \overline{\frac{\pi}{c}}$

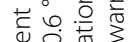

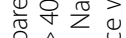

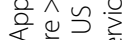

$<5$

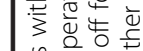

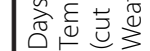

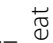

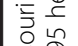

ڤั

$\sum \frac{1}{0}$

罂

吉恕

ते

N

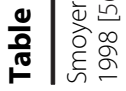


confidence level. Given the different approaches to analysis and quantitative formulation of the outcomes, changes in $R R$ over time are brought together graphically only for those papers which used similar methods and the same outcome metric (Figs. 2 and 3).

In those studies that examined changes in heat related mortality over the last century, most change appears to occur between the first (where risks appear substantively higher) and last part of the last century [36, 39, 44] (Fig. 2). Petkova et al. [36], appeared to show a slowing of the decrease in risk from the 1980s onwards (as the RR also approaches 1). Ha et al. [33] only analysed two points in time - both after 1990, and did not find a significant difference between RR of heat related mortality between the time points. Carson et al. [44] used larger time frames to compare risk and therefore results past 1980 cannot be visualised, however it appears that the decrease in risk after 1927 was substantial. The authors hypothesised that the large decrease seen in heat related mortality risk could be due to heat related deaths being caused by infectious diseases (such as diarrheal disease or septicaemia) in the first part of the century, but that with the epidemiological transition (the shift in burden of disease from infectious diseases to chronic non-communicable disease over time, due to improved sanitation and healthcare [48]), these have become less prominent over time. Of note, this study was the only one to use a weekly time series for the analysis of effect, which may explain some of the difference in pattern seen between this and other studies. Interestingly, Petkova et al. [36] specifically examined the effect of short term mortality displacement, and found it contributed less to heat related mortality over the last part of the century despite an ageing population.

In all studies where the proportions of deaths attributable to heat were analysed, deaths were decreased at the latest compared to earliest dates (see Table 1 and Fig. $3 a$ and b). Two of these papers $[37,45]$ only presented risks for two dates, making it difficult to comment on trend. Bobb et al. [37] found the overall (combined average of all 105 US cities analysed) attributable proportion of deaths to excess heat to be significantly ( $5 \%$ confidence level) less in 2005 compared to 1981. Carson et al. [44], using the same metric, also found the proportion of deaths attributable to temperatures above a given threshold to be significantly lower in the last time period compared to all others, though the pattern over the first 3 time periods is less clear. Two studies analysed deaths attributable to excess heat per million of the population (Donaldson et al. [45] and Davis et al. $[46,47])$. Donaldson et al. [45] compared two specific time periods in three locations. In North Carolina and South Finland the decreases in vulnerability were significant (5 \% confidence level) in all models. In South East England, the decrease was only significant in the model with control

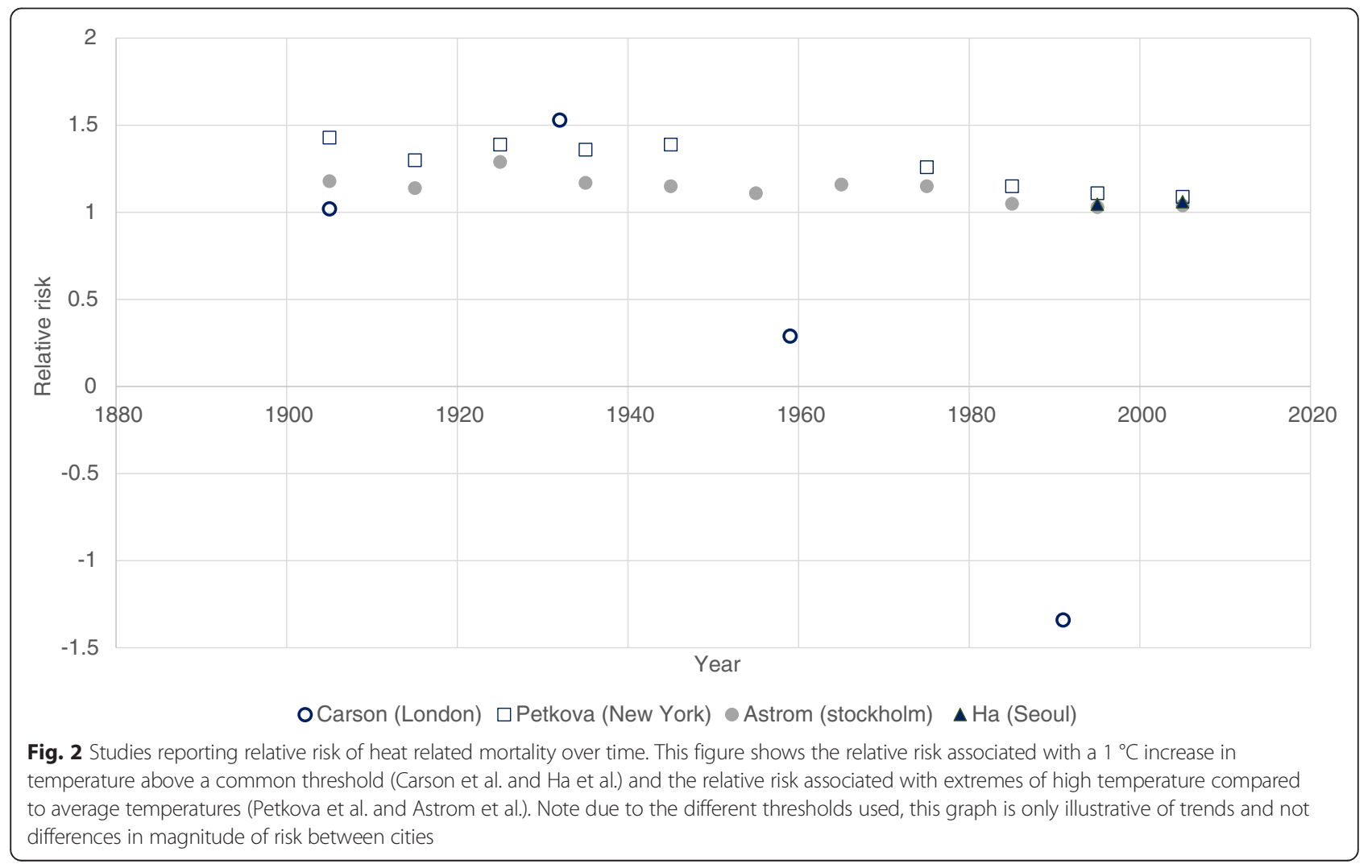



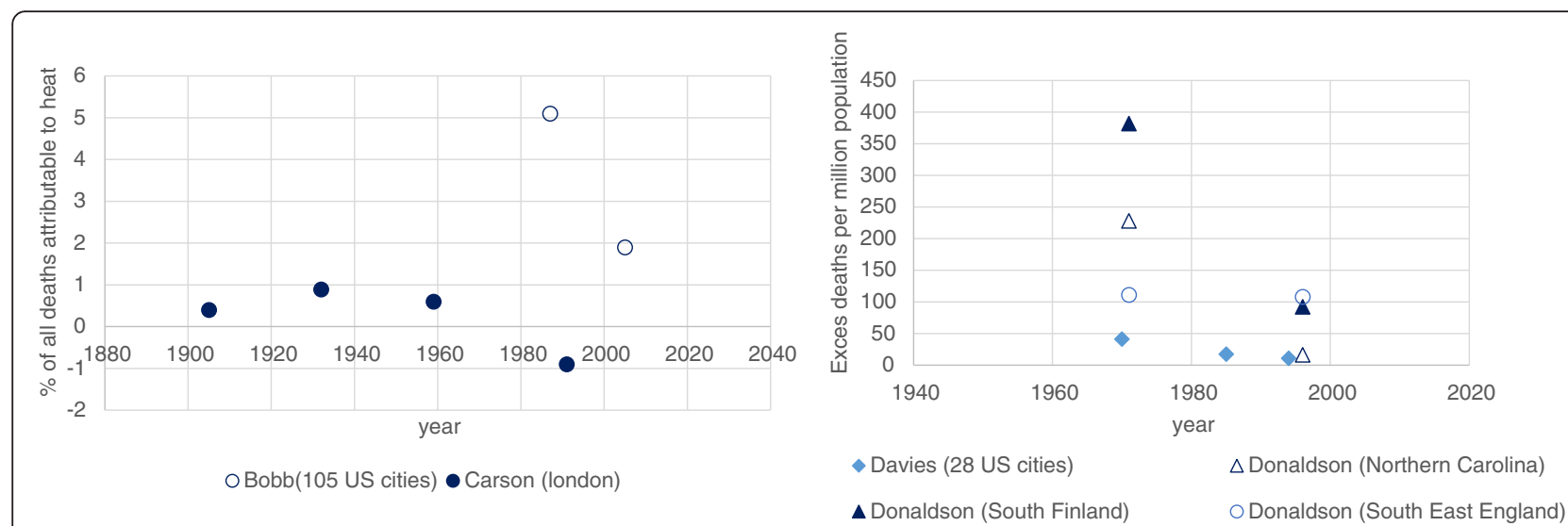

Fig. 3 Studies reporting heat related deaths over time. This figure shows studies comparing excess heat related mortality as a proportion of all deaths (left) and studies where excess heat related mortality was reported per million population (right)

for age and sex. However, it was not possible to represent the results from the adjusted models graphically as only the changes in excess deaths were reported (i.e. no baseline or final figures) Davies et al. examined heat risk in 28 US cities [46] and showed a decreasing trend across the three time points but included no information on significance.

Four papers analysed results using different methods/ outcomes to any other study and therefore are not represented graphically: Christidis et al. [41], Matzarakis et al. [40], Barnett [43] and Ekamper et al. [42].

Christidis et al. [41] investigated the hypothesis of 'adaptation' by comparing heat and cold related mortality estimates obtained by using regression slopes from either earlier or later years in the study. Regression slopes from earlier time periods in the study (1976) were used with weather data for the whole period to calculate heat and cold related mortality to demonstrate mortality with 'no adaptation'. Results obtained using the slope of the regression line from later years (2005) with the same weather data as a comparison were used to demonstrate deaths accounting for 'early adaptation'. These scenarios were compared to the actual heat and cold related mortality calculated with slopes and weather data from over the entire time period. They found actual heat related mortality increased by 0.7 deaths per million per year (using data from the whole time period) but if no adaptation had occurred heat related mortality would have increased by a larger amount (1.6 deaths per million per year over the period 1976-2005, calculated using regression slopes from the earlier time period with weather data from the whole period).

Matzaraki et al. [40], examined the change in excess mortalities attributable to different temperatures in 1970 and in 2007. For two of these ranges of temperature $\left(29^{\circ} \mathrm{C}\right.$ to $35{ }^{\circ} \mathrm{C}$ and $35{ }^{\circ} \mathrm{C}$ to $41{ }^{\circ} \mathrm{C}$ ) the excess mortality significantly decreased between the two time points. The last temperature range $\left(>41{ }^{\circ} \mathrm{C}\right)$ was reported as nonsignificant but had low numbers of deaths.

Barnett [43] used a case-crossover approach to examine the increase in risk of cardiovascular mortality with temperature in the US. Combined estimates for all the cities showed a significant decrease in vulnerability between the two time periods analysed (1987 and 2000).

Ekamper et al. [42] reported both shifts in the MMT (which increased over time) and slopes of regression analysis. They reported a decrease in vulnerability over time but did not test significance.

\section{Temporal changes in susceptibility to ambient cold}

Only five studies [39, 41-44] analysed the risk of cold related deaths over time, all as part of an overall analysis of temperature related mortality (i.e. none examined cold effects alone). Results of the two of these studies which reported the RR of cold related mortality below a given threshold over time are illustrated in Fig. 2 below.

Three of the five studies examining cold effects reported decreased susceptibility over time [39, 41, 44]. Carson et al. found that this decrease was significant (at the $5 \%$ level) in a London based study [44] (see Fig. 4 below). In a second UK based study, Christidis et al. [41], found that actual cold related mortality decreased by 85 deaths per million population per year over the period 1976-2006 (significance not reported). Using the same methods as described in the above section (on heat) to examine changes in cold related mortality under actual, 'adaptation' and 'no adaptation' scenarios they found that the decrease would have been smaller (47 deaths per million population per year) with 'no adaptation' (see also Table 1). Although Astrom et al. found a decrease in cold related mortality over time, it was found to be non-significant [39] except in the 0-14 year age category. 


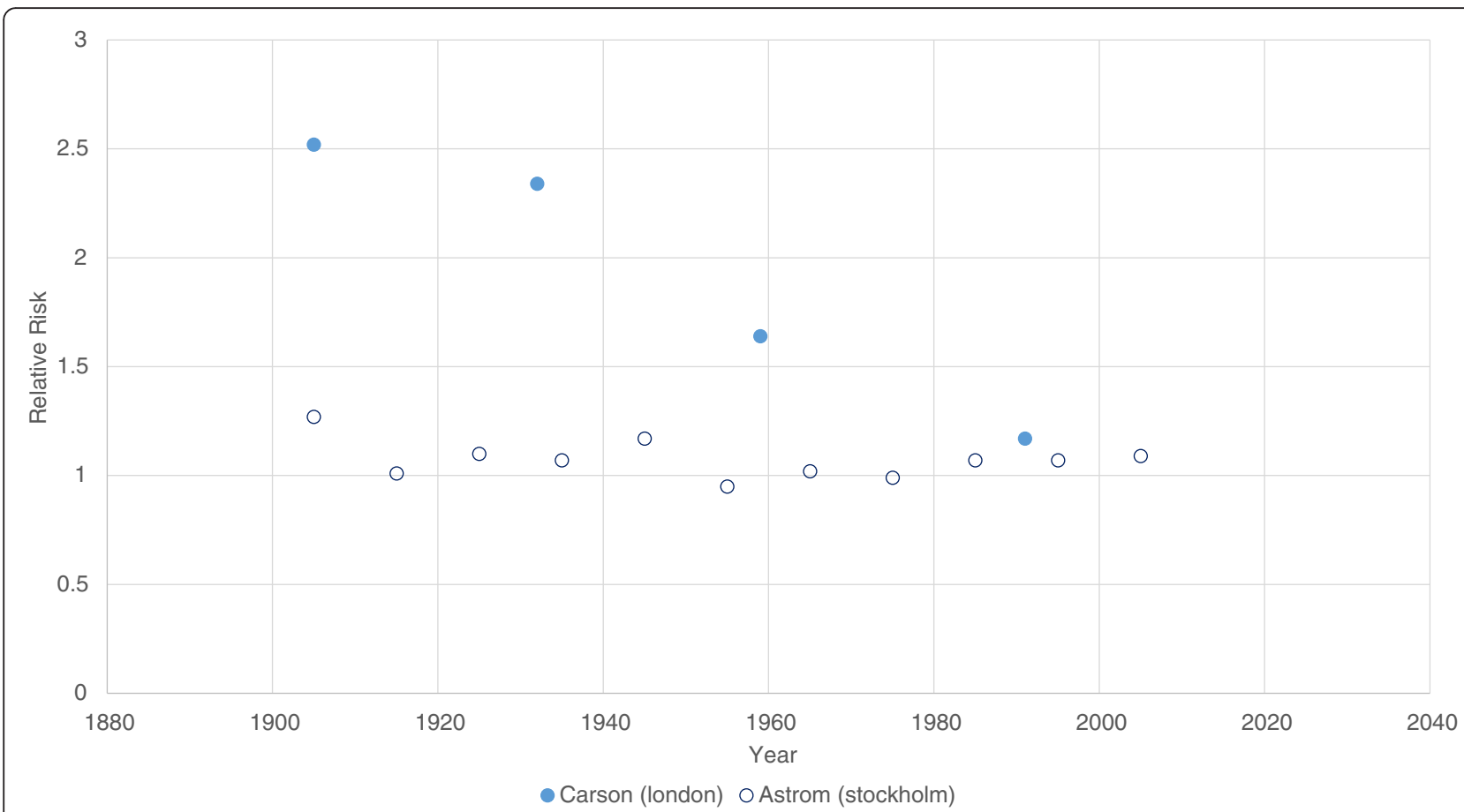

Fig. 4 Studies reporting the relative risk of cold related mortality over time. This figure illustrates the relative risks associated with a $1^{\circ} \mathrm{C}$ decrease in temperature below a common threshold

The study based in the US no clear evidence of any trend in cold related mortality over time [43] and a trend in cold related vulnerability was not clear in the study by Ekamper et al. [42].

Of note, all five studies had found a decreasing trend in heat related mortality.

One study exclusively examined the effects of cold temperatures on mortality in Spain by examining shifts in threshold for effects, but did not report quantitative results and so has not been specifically discussed in this review [49].

\section{Variation of results of heat and cold mortality by study characteristics Variation of effect by study design and metrics used}

It does not appear that the overall direction of effect over time was influenced by study design (time series, case crossover) or by the amount of time varying factors (e.g. seasonality, temporal trends, holidays etc.) controlled for by studies (see Additional file 1: Table S1a). Studies also used different approaches in either fixing the thesholds above which effects were modelled, or allowing these to vary across each time period analysed. This did not appear to alter the direction of effect demonstrated by studies (which consistently demonstrated decreasing susceptibility to heat effects regardless of precise design). However, the implications of these different choices are considered in the discussion section and in Table 3. Where sensitivity analyses were carried out, allowing definitions of extreme temperatures to vary by time periods analysed, small differences in results were seen within studies [39] (see Additional file 1: Table S1b) although the overall direction of effect remained unchanged.

Using excess heat or cold related deaths as an outcome includes many factors: the risk of mortality related to changes in temperature for the given time period, baseline mortality in the population and also the number of days at different temperatures above or below the threshold (where used) within that time period. In studies which used this metric [37, 41, 45,46], the number of heat-related deaths decreased over time in three studies. However, this could reflect changes in any of the factors mentioned above (e.g. RR, baseline mortality or temperature). It could be expected (though not always reported in these studies) that temperature has been increasing over the last century [1] and therefore the decreasing trend in excess deaths over time in these studies illustrates a decrease in vulnerability despite the increased temperature. One study [41] found that the number of heat related deaths did not decrease over time, but that the regression slope used to calculate these did.

Given that few studies included control for ambient air pollution in the main model it is difficult to know how this would have affected trends. It should be noted that the confounding role of air pollution is currently under debate [50]. In the study by Carson et al. [44], controlling 


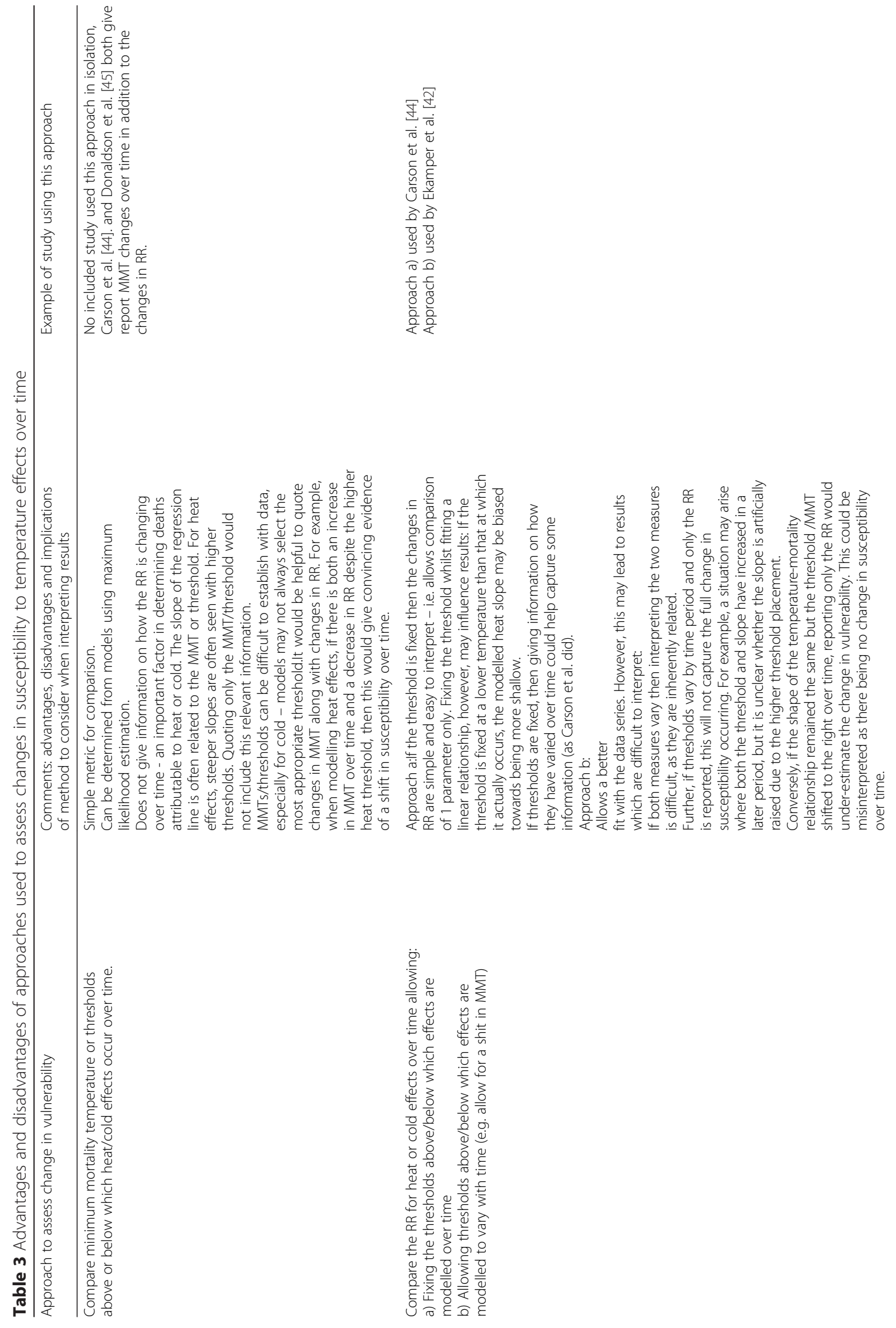




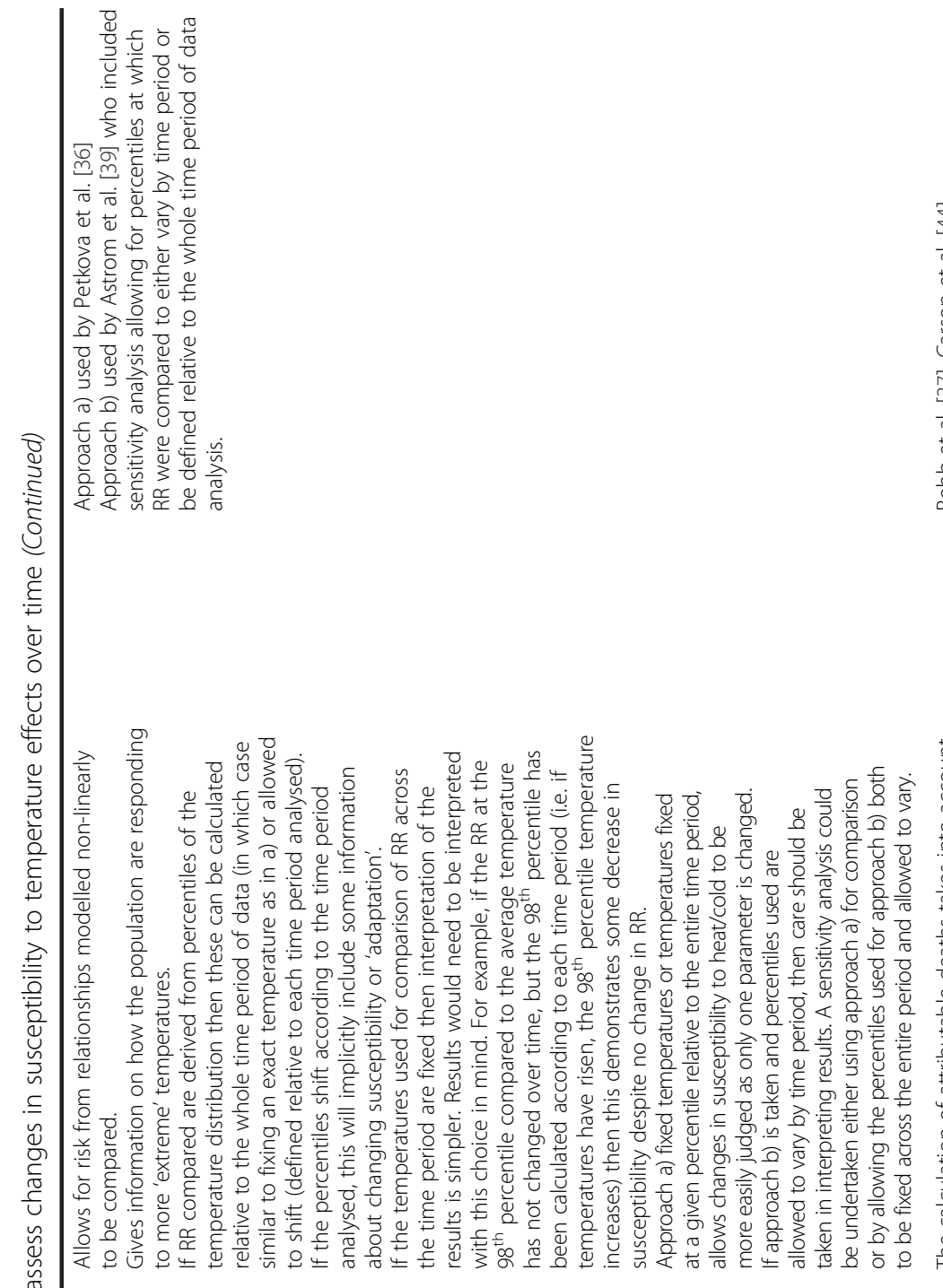

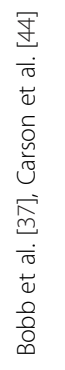

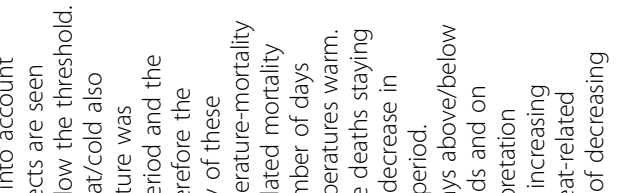

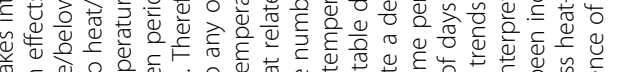

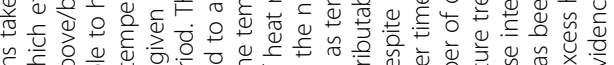

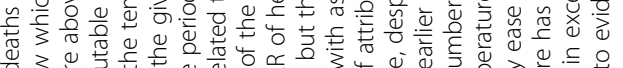

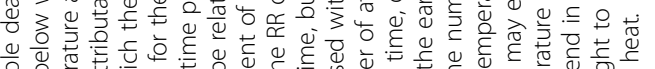

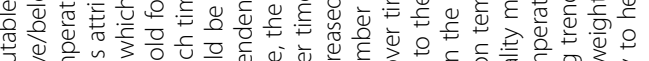

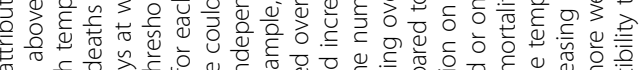

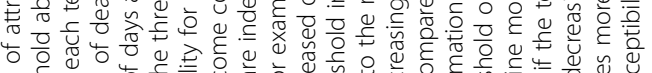

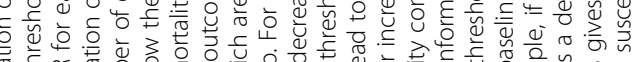

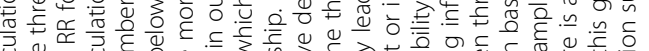

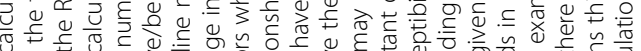

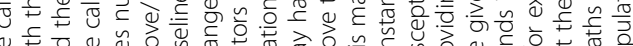

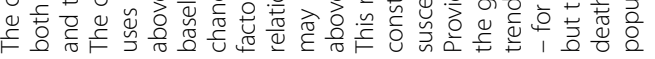




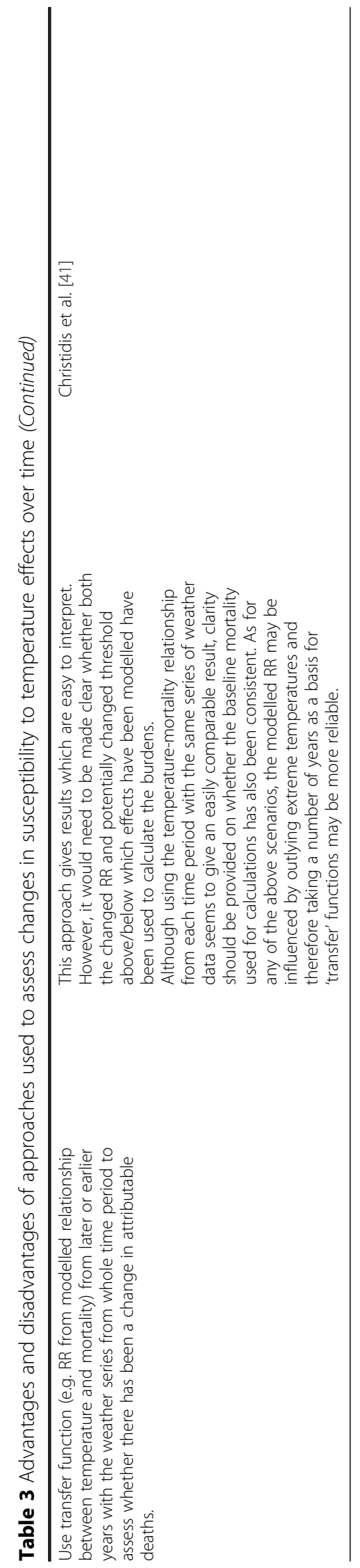


for air pollution did not affect the overall trend over time in cold related mortality, indeed individual RRs for each time period for cold-related mortality were higher after controlling for air pollution. Bobb et al. [37] provided information about models with pollution control as part of a sensitivity analysis. In this paper, when fine particulate matter was included in a linear model, the reduction in heat related mortality between the two time points was no longer significant at the $5 \%$ level (though the reduction remained significant in the non-linear model when air pollution was included).

Influenza is often thought to be a confounding factor when estimating the effects of cold (although whether it is considered a confounder in this relationship will depend on how much influenza survival and transmission rates are affected directly by ambient air temperature (i.e. placing it on the causal pathway between lower temperatures and mortality) as opposed to seasonal and behavioural factors such as school opening times (which occur independently of day to day variation in temperatures)). Three of the five papers reporting cold effects attempted to control for influenza, for example with the inclusion of an indicator for influenza within the models [39] or where flu data was not available by excluding years of known influenza epidemics [42, 44].

\section{Variation of effect by subgroup analysis}

Where studies examined temperature related mortality by specific subgroups such as cardiovascular or respiratory mortality [37, 38, 43, 44], decreases in these subgroups were seen for the effect of heat and in three of the studies this was significant [36, 37, 43]. Of interest, in the study by $\mathrm{Ha}$ et al. [38], there was a (nonsignificant) decrease in risk of cardiovascular mortality above the temperature threshold in contrast to a (non-significant) increase in all-cause mortality. Carson et al. [44] reported decreases in cardio-vascular and respiratory deaths were less prominent than for all-cause mortality. However, this study analysed a much longer time period than others examining outcome specific mortality and therefore factors such as the epidemiological transition may explain some of the differences. As previously mentioned, this study used weekly data which may also affect the patterns in results seen between different causes of death.

Where results were analysed by age group, the majority of studies found that the largest temporal reductions in mortality were in the older age groups [36, 37, 39]. Barnett [43] and Donaldson et al. [45] only analysed the results in the elderly and over $55 \mathrm{~s}$ respectively and both found decreases in vulnerability to heat.

\section{Variation of effect by location: between and within studies}

The variety in approaches used for analysis makes it difficult to compare the variation between studies of effects seen across geographical areas. However, results presented so far have been for area or national level aggregated estimates. Four papers [37, 43, 45, 46] included multiple cities or areas within the same paper (i.e. same methods used). For those which analysed multiple cities within the US [37, 43, 46] some heterogeneity in results was seen. Bobb et al. [37] found that 74/105 cities displayed a significant decrease in excess heat related mortality between 1987 and 2005 and that cities with cooler climates had a larger decline in heat related mortality risk, though these cities also had the highest heat related mortality at the start of the time period. The cities with the largest increase in prevalence of air conditioning over the time period also had the largest declines in mortality, though this was not a statistically significant association. For one city in Southern California, susceptibility increased over time (not statistically significant at the $5 \%$ confidence level). Davies et al. [46] examined 28 US cities over an earlier time period. They found heat related mortality rates had declined in $42 \%$ of the cities but that two cities on the West coast (Seattle and Washington) had an increased number of excess deaths in the later time periods. They also reported that 12 cities (in the South) no longer displayed evidence of a threshold temperature above which heat mortality occurred (see Table 1 for details). Barnett [43] found the largest declines in heat related mortality risk in the US were in the North West, North East, Industrial West and Southern California. The reason for the difference in regional declines seen between these two papers cannot be conclusively determined, though some may be attributable to the difference in levels of aggregation of data (for example, Barnett uses regions, whereas Davies et al.. examine metropolitan areas), the different time periods analysed between studies and potentially the difference in methods used.

Donaldson et al. [45] analysed three different geographical areas (Southern Finland, Northern Carolina and Southern England) and found that the decrease in heat related mortality was smallest in South East England.

\section{Susceptibility to extreme temperature events}

Six papers were identified that examined differences in all-cause mortality between two different heatwaves or between heatwaves occurring over a number of years in the same location [51-56] (see Table 2 for details). All studies were from high or middle-high income countries. Most of these papers use an episode analysis approach to compare the expected and actual deaths during heatwaves. The approaches taken to selecting an appropriate baseline (for the expected deaths) varied between studies (Table 2) from using a moving 15-30 day average [52] to 
using more complex models over longer time periods (e.g. [51, 53, 55]). One study compared the absolute number of deaths occurring in two heatwave periods [54]. In comparing different heatwaves, some papers (e.g. [56]) made allowances for the different characteristics of various heatwaves by using model parameters from previous years with weather data from a heatwave in later years and vice versa. Other papers did not make such allowances, but two reported a decrease in heatwave related mortality despite a general increase in the maximum temperature encountered in later heatwaves.

Four papers reported decreased heatwave related mortality in later years [51-54], of which two reported a measure of statistical significance for this. Using a test for linear trend, Kysely et al. [51] found a significant decrease in the effects of heatwaves over the years. Fouillet et al. [53] found the number of deaths to be significantly fewer than those expected when derived from a predictive model based on previous years data.

One study reported no pattern in effects of heatwaves over time [55] and one found a non-significant increase in expected heatwave related deaths in a later year, despite there being an increase in air conditioning over this time and having made allowances for differences in heatwave characteristics [56]. This study used data from Chicago and it was hypothesised that this could be due to the increase in number of persons in the eldest age category between the two events and the number of older persons living below the poverty line (in the US, socio-economic status has been associated with heat related outcomes $[57,58]$, possibly because it relates to access to working air conditioning which is predictive of reduced heat related mortality [59-61]).

Where a decrease in mortality was seen, potential explanations included the introduction of heat health warning systems (HHWS), increased prevalence of air conditioning, improved urban design and living standards (Table 2). No study attempted to quantify these relationships.

No studies were located that specifically examined the effects of cold snaps over time.

\section{Discussion}

Of the eleven papers that examined variations in the $R R$ of, or heat related mortality over time, all except one [38] found some evidence of decreasing susceptibility. In five of these, this decrease was significant at the $5 \%$ confidence level (either analysed as trend over time or the difference between two discrete time points). Susceptiblity to heat appeared to stabilise over the last part of the century in those studies which covered that time period and in studies analysing more than one location, the magnitude of the decrease varied according to region or city. Where examined, studies found a decrease in cardio-vascular and respiratory heat related mortality.

Comparison of the magnitude of the changes in RR or temperature related mortality between studies is difficult, due to the variety of outcome measures and approaches used to model the temperature-mortality relationships. For example, where thresholds have been used, some studies have fixed temperature thresholds across the whole time period [44] and others have allowed them to vary within time periods analysed $[42,46]$. This is important due to the inherent link between the temperature at which the threshold is set and the slope of the exposure-response regression line. There are further inherent limitations of approaches used by individual studies. For example, results of studies which use heat related mortality as an outcome (rather than the RR of death at different temperatures) are also affected by changes in baseline mortality and temperature over time. This can make it difficult to ascertain how much susceptibility to temperature itself is changing over time. Table 3 discusses in more detail the approaches used by individual studies included in this review to assess changes in vulnerability. Whilst we have not gone so far as to recommend one specific approach be used, we do highlight specific aspects of each study design that have implications for the interpretation and comparability of results obtained from these studies (see Table 3). Residual confounding is likely in many of the studies - although the importance of air pollution as a confounder is currently under debate [50], studies examining year round risk also had incomplete control for influenza and other seasonal trends or trends in mortality over time. The results of studies examining temperature related health risks are also aggregated to at least city level, which may lead to a masking of differences in vulnerability of certain population subgroups. It would be important to ascertain, for example, whether different sections of society (e.g. age groups, rural vs. urban populations or groups of different socio-economic status) display differences in their changes in risk of heat related mortality over time. For example, the urban heat island is likely to alter heat related risk and with increasing urbanisation, understanding how urban populations can and have adapted to heat will be important to inform future planning of cities.

There are also limitations of the body of literature reviewed as a whole. For example, there are no studies specifically from low income settings, where planned adaptive measures may be different to or less prevalent than those used in high income settings. Changes in temperature related mortality over time could be different in these contexts. Secondly, the number of studies is small and, due to differences in outcome measures and approaches used, is difficult to draw conclusions from. Also, many studies [38, 39, 42-45] have not analysed factors contributing to changes in risk over time. Although studies have controlled for general long-term trends in mortality 
(which should, for example, pick up long term trends in all-cause mortality), whether cause-specific (e.g. cardiovascular) mortality has changed specifically due to adaptation to heat or due to reduced cardio-vascular risk factors in general cannot be determined from the models. Only two papers made an attempt to quantitatively attribute changes in vulnerability to specific adaptive measures $[37,46]$. Each found non-significant associations between air conditioning prevalence (see Additional file 1: Table S1b) changes over time and heat related mortality within cities [37] and overall [46]. Other studies included qualitative explanations for the reduction in heat related mortality over time, for example improved urban planning and building design $[36,39,44,46]$, increased living standards and a reduction in risk factors for conditions such as cardiovascular or respiratory morbidity [36]. These possible modifiers of the heat-mortality relationship have been summarised in Fig. 5. Identifying factors which have contributed to such changes could be used to inform environmental and health policy and future urban planning.

The possible slowing of the decline in heat related mortality over the latter part of the last century is interesting. This may, in part, be related to the epidemiological transition (for example, in the later part of the last century, declining susceptibility due to fewer heat related deaths from infectious causes would have occurred but heatrelated cardiovascular mortality, for example, may be harder to prevent) but it also potentially demonstrates a limit to 'adaptation'. For example, there may be limits to both physiological adaptation and adaptive changes in infrastructure. Further studies which examine trends over time and in particular in more recent years are necessary to better understand this. Better integeration of physiological and epidemiological research would enable improved understanding of the importance that physiological adaptation can play within populations.

Overall, studies which have examined the effects of specific heatwave events on mortality over time, have found a reduction of heat-related mortality in later years [51-54]. These studies are not as robust in design as time-series or case-crossover approaches, and particular effects of a given heatwave may vary due to factors not captured in all definitions (e.g. intensity, temperature related to previous days etc.), that is to say that no two heatwaves are the same and have different characteristics which can modify the temperature-mortality relationship [62].

Despite a decreasing vulnerability to heat over time, there is little consistent evidence for decreasing cold related mortality, especially over the latter part of the last century. This may be unexpected, given advancements in housing design and in medical care. However, this should be considered in the context of the small number of studies that examined cold, and fewer that included information on the statistical significance. The lack of reduction in vulnerability to cold remains important as there is some evidence that maximum temperatures are rising faster than minimum temperatures [63]. Conversally, it might be expected by some, that as the climate has warmed over the last century, populations would become less vulnerable to heat and potentially more vulnerable to cold. However, there is no evidence of increased vulnerability to cold, either in terms of cold related mortality or

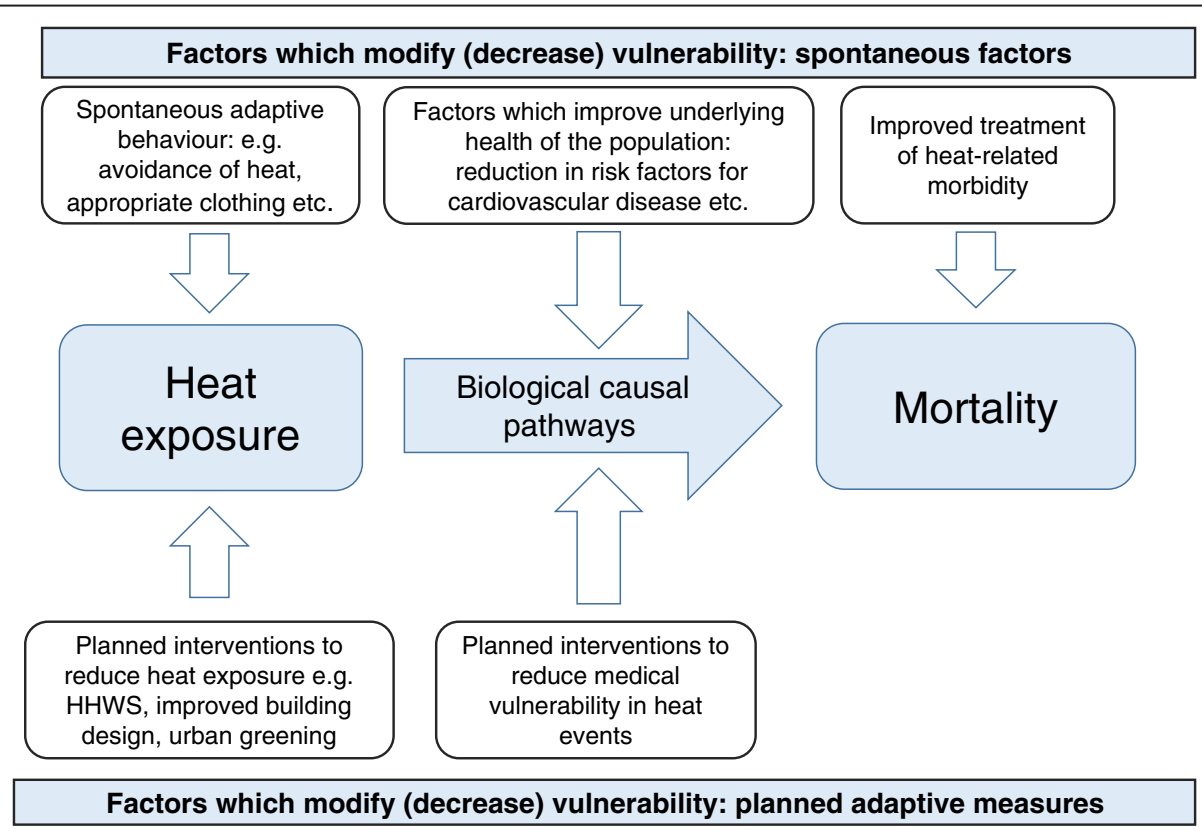

Fig. 5 Factors accounting for changes in vulnerability to heat over time 
relative risk. This does suggest that, at least at an ecological level, there is no current evidence that 'maladaptation' has led to an increased vulnerability to cold over time.

Reasons for the differences over time between heat and cold related mortality have not been quantitatively explained in any papers. Therefore, different explanations should be examined: if improvements in the standard of living and reduction in risk factors for co-morbidities/improved medical care have contributed to some of the temporal decline in heat related mortality, it is reasonable to expect similar reductions in cold related mortality if similar pathways of causation exist. Some of the difference in trend may be due to different causal pathways for heat and cold exposure, for example, cold related mortality is known to occur over longer lag periods and mortality displacement (harvesting) is thought to be less important. It is also hpossible that physiological acclimatisation contributes more substantially to decreasing heat related mortality than to cold related mortality. For example, in their paper, Kysely et al. [51] specifically look at late summer versus early summer mortality from heat waves and find that this decreases over time. Physiological acclimatisation and changes in this over time have not been specifically evaluated in this review and would be an interesting area of further research. As the climate has warmed, the use of air conditioning and heat warning systems/health messaging are also offered as hypotheses for decreased heat related mortality, where these interventions are present. There have also been substantial changes in building design over time. However, whilst some of these might reduce vulnerability to heat specifically, others, such as the increased proportion of people living in flats might be expected to have the opposite effect [64]. Understanding differences in trends between heat and cold related vulnerability represents an important gap in knowledge.

\section{Evidence from other studies and cities}

Studies of differing vulnerability to temperature across geographical regions [21, 24, 26, 65] are often cited as potential evidence for adaptation. A review of these studies [27] used meta-regression to establish city-level characteristics associated with the heat-mortality relationship, demonstrating thresholds were generally higher in communities living closer to the equator. It also found that decreasing GDP, increasing age and population density were associated with increased relative risks of mortality from heat. This evidence is generally consistent with the findings of this review: many of the studies in this review hypothesised that improved standards of living and healthcare would reduce risk factors for disease and also heat exposure, therefore reducing susceptibility to heat over time. It is possible, however, that some cities have become more densely populated which may have increased vulnerability to heat, for example due to higher proportions of the population living in flats and risks of building overheating. However, while comparing results across cities or regions may implicitly include adaptation to temperature over time, it cannot give an estimate of how quickly or by how much community vulnerability can change.

This review provides suggestive evidence of decreasing susceptibility to heat over time. Due to the information included in the studies it cannot, however, determine how much specific adaptive measures (such as the use of cooling systems or HHWS) have contributed to changes compared to general improvements in healthcare and wellbeing in the population. The importance of air conditioning has, however, been demonstrated in other studies [57-61]. Studies, such as one undertaken in migrants which showed reduced vulnerability to heat in those who were born in Southern compared to Northern Italy [66] lend some evidence that physiological and behavioural adaptations to heat could be important and last over population lifespans. Examining trends in cities over time either within the same country or across countries with similar life expectancies and level of development could help further understand the role of adaptation. For example, vulnerability to heat across the US over time was shown to differ by city in the three multi-city studies presented here [37, 43, 46]. Whilst there are likely to be differences in patterns of risk factors and mortality across the US, the overall trend in these factors over time might be broadly expected to be the same. Differences in heat related vulnerability, compared to other specific trends over time by city could support the hypothesis that adaptation to heat specifically has occurred in these areas. Further studies would be required to substantiate this and differentiate different levels of underlying vulnerability across regions.

\section{Implications for future climate change assessments and policy}

A systematic review of future temperature related mortality projections synthesised evidence from 14 studies [67]. Of these, it was found that only half included assumptions about adaptation or changes in vulnerability in future estimates. Methods used to account for adaptation varied from the use of analogue cities $[68,69]$ analogue summers [70] and assuming adaptation to heat for a pre-determined number of degrees Celsius [71, 72]. The merits and limitations of each of these approaches have been discussed elsewhere [73-75]. Whilst the comparison of vulnerability to temperatures across regions can be used to inform the 'analogue cities' approach and differences in early versus late summers can be used to inform how much short term acclimatisation can achieve, the use of past declines in vulnerability has not 
been used, to our knowledge, to inform any future risk assessments. It could be argued that past trends cannot be used to inform future estimates of adaptation - the climate is projected to warm faster over the next century than in the past [1] and it is uncertain whether future populations will be able to adapt at the same rate (for example, some 'markets' for air-conditioning in the US were already thought to be saturated [46]). It is also unknown whether general health gains which lead to reduced vulnerability have been achieved. Nonetheless it is important to recognise that baseline vulnerability to heat in particular has changed across a number of settings. Baseline periods used in a number of studies projecting future temperature related risk studies published over the last decade span a period from the $1960 \mathrm{~s} / 70 \mathrm{~s}$ to the 1990s/2000s [71, 76-78], though some studies - especially those published most recently, have used a more recent baseline period which is likely to improve future estimates [28, 79-81]. Given the trends in mortality observed, estimates of future risk could be improved to better reflect contemporary temperature related health risk. Where this has not been done, projections of future heat related mortality may have been over-estimated.

\section{Conclusions}

There is evidence that the risk of heat related mortality has changed over the last century and more recently. Further studies would be required to improve knowledge in this area, for example to understand the rate of changes in susceptibility more recently and whether changes are occurring at equal rates across sectors of society. Attribution of decreases in mortality to planned adaptive measures may help to inform future actions or policy, as would studies that specifically examine the effectiveness of certain adaptive actions. There are potential policy implications in the lack of decreasing vulnerability to cold. Adaptive efforts should not focus on heat alone, despite warming temperatures. Recent climate change risk assessments (e.g. [28]) show that the risk from cold is expected to account for most of the temperature related risk until late in the century (this is because of the magnitude of the $R R$ and because there remain many more days below cold thresholds until this time). Therefore, any adaptive strategies would ideally reduce the risk from both heat and cold in order to prepare for both short and longer term temperature related risk, and urban and housing design with other co-benefits to health should be emphasised (e.g. [82]). Given the additional risk in urban areas due to the urban heat island effect [83] understanding the risk that future temperatures are likely to pose to health, and how populations can adapt equitably using solutions with co-benefits, is especially important in urbanised societies to plan for healthy and sustainable cities.
Lastly, when considering adaptation in impact assessments of future temperature related risk, sensitivity analyses which include differences in baseline vulnerability could improve understanding of future risk, as would assessments which could include, where possible, effects of certain specific adaptive measures on future heat related risk.

\section{Additional files}

Additional file 1: Table S1a. Features of Studies Examining Changes in Heat and Cold Susceptibility over Time. Table S1b. Results of studies examining the change in heat/cold susceptibility over time. (ZIP $50 \mathrm{~kb}$ )

Additional file 2: Peer review reports. (PDF $62 \mathrm{~kb}$ )

\section{Abbreviations}

CRM: Cold related mortality; DF: Degrees of freedom; GDP: Gross domestic product; HRM: Heat related mortality; HW: Heatwave; MMT: Minimum mortality temperature; PAT: Physiological apparent temperature; PM10: Particulate matter $\leq 10 \mu \mathrm{m}$ in diameter; RR: Relative risk.

\section{Competing interests}

The authors declare that they have no competing interests.

\section{Authors' contributions}

KA conceived the idea for review and drafted the original manuscript. All authors contributed to the design of the review. $\mathrm{CH}, \mathrm{SH}$ and SV provided critical input to the paper, tables and figures. All authors read and approved the manuscript.

\section{Acknowledgments}

KA was supported by the PHE PhD studentship scheme. The research was partly funded by the National Institute for Health Research Health Protection Research Unit (NIHR HPRU) in Environmental Change and Health at the London School of Hygiene and Tropical Medicine in partnership with Public Health England (PHE), and in collaboration with the University of Exeter, University College London, and the Met Office. The views expressed are those of the authors and not necessarily those of the NHS, the NIHR, the Department of Health or Public Health England. We are grateful for the help of Caroline DeBrun at PHE with searching the literature databases.

\section{Declarations}

Public Health England has provided funding for the publication fee of this article.

This article has been published as part of Environmental Health Volume 15 Suppl 1, 2016: Healthy-Polis: Challenges and Opportunities for Urban Environmental Health and Sustainability. The full contents of the supplement can be found at http://www.ehjournal.net/supplements/15/S1.

\section{Peer review}

Peer review reports for this article are attached as Additional file 2.

Published: 8 March 2016

\section{References}

1. Stocker TF, Qin DG, Plattner K, Tignor M, Allen SK, Boschung J, et al. The Physical Science Basis. Contribution of Working Group I to the Fifth Assessment Report of the Intergovernmental Panel on Climate Change. In: IPCC. 2013. p. 1-30.

2. Schar C, Vidale PL, Luthi D, Frei C, Haberli C, Liniger MA, et al. The role of increasing temperature variability in European summer heatwaves. Nature. 2004;427(6972):332-6.

3. Meehl GA, Tebaldi C. More intense, more frequent, and longer lasting heat waves in the 21st century. Science. 2004;305(5686):994-7.

4. Christidis N, Jones GS, Stott PA. Dramatically increasing chance of extremely hot summers since the 2003 European heatwave. Nat Clim Chang. 2015;5(1):46-50. 
5. Jones B, O'Neill BC, McDaniel L, McGinnis S, Mearns LO, Tebaldi C. Future population exposure to US heat extremes. Nat Clim Chang. 2015;5(7):652.

6. Watts N, Adger WN, Agnolucci P, Blackstock J, Byass P, Cai W, et al. Health and climate change: policy responses to protect public health. Lancet. 2015. doi:10.1016/50140-6736(15)60854-6.

7. Guo Y, Gasparrini A, Armstrong B, Li S, Tawatsupa B, Tobias A, et al. Global variation in the effects of ambient temperature on mortality: a systematic evaluation. Epidemiology. 2014;25(6):781-9.

8. Cheng J, Xu Z, Zhu R, Wang X, Jin L, Song J, et al. Impact of diurnal temperature range on human health: a systematic review. Int J Biometeorol. 2014:58(9):2011-24

9. Oudin Astrom D, Bertil F, Joacim R. Heat wave impact on morbidity and mortality in the elderly population: a review of recent studies. Maturitas. 2011;69(2):99-105.

10. Bi P, Williams S, Loughnan M, Lloyd G, Hansen A, Kjellstrom T, et al. The effects of extreme heat on human mortality and morbidity in Australia: implications for public health. Asia Pac J Public Health. 2011;23(2 Suppl):27S-36.

11. Basu R. High ambient temperature and mortality: a review of epidemiologic studies from 2001 to 2008. Environ Health. 2009:8:40.

12. Xie H, Yao Z, Zhang Y, Xu Y, Xu X, Liu T, et al. Short-term effects of the 2008 cold spell on mortality in three subtropical cities in Guangdong Province, China. Environ Health Perspect. 2013;121(2):210-6.

13. Wanitschek M, Ulmer H, Sussenbacher A, Dorler J, Pachinger O, Alber HF. Warm winter is associated with low incidence of ST elevation myocardia infarctions and less frequent acute coronary angiographies in an alpine country. Herz. 2013;38(2):163-70.

14. Gomez-Acebo I, Llorca J, Dierssen T. Cold-related mortality due to cardiovascular diseases, respiratory diseases and cancer: a case-crossover study. Public Health. 2013;127(3):252-8.

15. Gill RS, Hambridge HL, Schneider EB, Hanff T, Tamargo RJ, Nyquist P. Falling temperature and colder weather are associated with an increased risk of aneurysmal subarachnoid hemorrhage. World Neurosurgery. 2013;79(1):136-42.

16. Guo Y, Jiang F, Peng L, Zhang J, Geng F, Xu J, et al. The association between cold spells and pediatric outpatient visits for Asthma in Shanghai, China. PLOS ONE. 2012;7(7):e42232.

17. Chau PH, Wong M, Woo J. Challenge to long term care for the elderly: cold weather impacts institutional population more than community-dwelling population. J Am Med Dir Assoc. 2012;13(9):788-93.

18. Monteiro A, Velho S, Sousa C. Why should we focus in cold extremes health negative outcomes in Mediterranean climate like Porto, Portugal? Eur J Epidemiol. 2013;1:S177.

19. Guo Y, Li S, Zhang Y, Pan X, Adrian B, Tong S. The effects of ambient temperature on cerebrovascular deaths in five cities, China. Epidemiology. 2012;1:S323.

20. Guo Y, Barnett AG, Tong S. High temperatures-related elderly mortality varied greatly from year to year: important information for heat-warning systems. Sci Report. 2012;2:830

21. Baccini M, Biggeri A, Accetta G, Kosatsky T, Katsouyanni K, Analitis A, et al. Heat effects on mortality in 15 European cities. Epidemiology. 2008;19(5):711-9.

22. Hess JJ, Eidson M, Tlumak JE, Raab KK, Luber G. An evidence-based public health approach to climate change adaptation. Environ Health Perspect. 2014;122(11):1177-86.

23. IPCC., Barros VR, Field CB, Dokken DJ, Mastrandrea MD, al. MKe: Climate Change 2014: impacts, adaptation and vulnerablity. Contribution of working group II to the fifth assessment report of the Intergovernmental panel on climate change. In. Edited by Cambridge University Press C, UK; 2014.

24. Curriero FC, Heiner KS, Samet JM, Zeger SL, Strug L, Patz JA. Temperature and mortality in 11 cities of the eastern United States. Am J Epidemiol. 2002:155(1):80-7.

25. Ma W, Chen R, Kan H. Temperature-related mortality in 17 large Chinese cities: How heat and cold affect mortality in China. Environ Res. 2014;134:127-33

26. McMichael AJ, Wilkinson P, Kovats RS, Pattenden S, Hajat S, Armstrong B, et al. International study of temperature, heat and urban mortality: the 'ISOTHURM' project. Int J Epidemiol. 2008;37(5):1121-31.

27. Hajat S, Kosatky T. Heat-related mortality: a review and exploration of heterogeneity. J Epidemiol Community Health. 2010;64(9):753-60.

28. Vardoulakis S, Dear K, Hajat S, Heaviside C, Eggen B, McMichael A. Comparative assessment of the effects of climate change on heat- and cold-related mortality in the United Kingdom and Australia. Environ Health Perspect. 2014;122(12):1285-92.
29. Gasparrini A, Guo Y, Hashizume M, Lavigne E, Zanobetti A, Schwartz J, et al. Mortality risk attributable to high and low ambient temperature: a multicountry observational study. Lancet. 2015;386(9991):369-75.

30. Toloo G, FitzGerald G, Tong S. Managing health risks of extreme weather events: need for a systematic approach. Aust N Z J Public Health. 2014;38(1):90-1.

31. Toloo GS, Fitzgerald G, Aitken P, Verrall K, Tong S. Are heat warning systems effective? Environ Health. 2013;12:27.

32. Tompkins EL, Adger WN, Boyd E, Nicholson-Cole S, Weatherhead K, Arnell N. Observed adaptation to climate change: UK evidence of transition to a well-adapting society. Global Environ Chang. 2010;20(4):627-35.

33. Bouzid M, Hooper L, Hunter PR. The effectiveness of public health interventions to reduce the health impact of climate change: a systematic review of systematic reviews. PLoS ONE. 2013;8(4):e62041.

34. Boeckmann M, Rohn I. Is planned adaptation to heat reducing heat-related mortality and illness? A systematic review. BMC Public Health. 2014:14:1112.

35. Gupta S, Carmichael C, Simpson C, Clarke MJ, Allen C, Gao Y, et al. Electric fans for reducing adverse health impacts in heatwaves. Cochrane Database Syst Rev. 2012;7:CD009888.

36. Petkova EP, Gasparrini A, Kinney PL. Heat and mortality in New York City since the beginning of the 20th century. Epidemiology. 2014;25(4):554-60.

37. Bobb JF, Peng RD, Bell ML, Dominici F. Heat-related mortality and adaptation to heat in the United States. Environ Health Perspect. 2014;122(8):811-6.

38. Ha J, Kim H. Changes in the association between summer temperature and mortality in Seoul, South Korea. Int J Biometeorol. 2013;57(4):535-44.

39. Astrom DO, Forsberg B, Edvinsson S, Rocklov J. Acute fatal effects of shortlasting extreme temperatures in Stockholm, Sweden: evidence across a century of change. Epidemiology. 2013;24(6):820-9.

40. Matzarakis A, Muthers S, Koch E. Human biometeorological evaluation of heat-related mortality in Vienna. Theor Appl Climatol. 2011;105(1/2):1-10.

41. Christidis N, Donaldson GC, Stott PA. Causes for the recent changes in cold- and heat-related mortality in England and Wales. Clim Chang. 2010;102(3/4):539-53.

42. Ekamper P, Duin G. 150 Years of temperature-related excess mortality in the Netherlands. Demogr Res. 2009;21 (14):385-426.

43. Barnett AG. Temperature and cardiovascular deaths in the US elderly: changes over time. Epidemiology. 2007;18(3):369-72.

44. Carson C, Hajat S, Armstrong B, Wilkinson P. Declining vulnerability to temperature-related mortality in London over the 20th century. Am J Epidemiol. 2006;164(1):77-84.

45. Donaldson GC, Keatinge WR, Nayha S. Changes in summer temperature and heat-related mortality since 1971 in North Carolina, South Finland, and Southeast England. Environ Res. 2003;91(1):1-7.

46. Davis RE, Knappenberger PC, Michaels PJ, Novicoff WM. Changing heat-related mortality in the United States. Environ Health Perspect. 2003;111(14):1712-8.

47. Davis RE, Knappenberger PC, Novicoff WM, Michaels PJ. Decadal changes in summer mortality in U.S. cities. Int J Biometeorol. 2003;47(3):166-75.

48. Omran AR. The epidemiologic transition. A theory of the epidemiology of population change. Milbank Mem Fund Q. 1971;49(4):509-38.

49. Miron IJ, Montero JC, Criado-Alvarez JJ, Linares C, Diaz J. Intense cold and mortality in Castile-La Mancha (Spain): study of mortality trigger thresholds from 1975 to 2003. Int J Biometeorol. 2012;56(1):145-52.

50. Buckley JP, Samet JM, Richardson DB. Commentary: Does air pollution confound studies of temperature? Epidemiology. 2014;25(2):242-5.

51. Kyselý J, Plavcová E. Declining impacts of hot spells on mortality in the Czech Republic, 1986-2009: adaptation to climate change? Clim Chang. 2012;113(2):437-53.

52. Kysely J, Kriz B. Decreased impacts of the 2003 heat waves on mortality in the Czech Republic: an improved response? Int J Biometeorol. 2008;52(8):733-45.

53. Fouillet $A$, Rey $G$, Wagner $V$, Laaidi $K$, Empereur-Bissonnet $P$, Le Tertre A, et al. Has the impact of heat waves on mortality changed in France since the European heat wave of summer 2003? A study of the 2006 heat wave. Int J Epidemiol. 2008;37(2):309-17.

54. Tan J, Zheng Y, Song G, Kalkstein LS, Kalkstein AJ, Tang X. Heat wave impacts on mortality in Shanghai, 1998 and 2003. Int J Biometeorol. 2007: 51(3):193-200

55. Rey G, Jougla E, Fouillet A, Pavillon G, Bessemoulin P, Frayssinet $P$, et al. The impact of major heat waves on all-cause and cause-specific mortality in France from 1971 to 2003. Int Arch Occup Environ Health. 2007;80(7):615-26.

56. Smoyer KE. A comparative analysis of heat waves and associated mortality in St. Louis, Missouri-1980 and 1995. Int J Biometeorol. 1998;42(1):44-50. 
57. Harlan SL, Declet-Barreto JH, Stefanov WL, Petitti DB. Neighborhood effects on heat deaths: social and environmental predictors of vulnerability in Maricopa County, Arizona. Environ Health Perspect. 2013;121(2):197-204.

58. Zanobetti A, O'Neill MS, Gronlund CJ, Schwartz JD. Susceptibility to mortality in weather extremes: effect modification by personal and small-area characteristics. Epidemiology. 2013;24(6):809-19.

59. Bouchama A, Dehbi M, Mohamed G, Matthies F, Shoukri M, Menne B. Prognostic factors in heat wave related deaths: a meta-analysis. Arch Intern Med. 2007;167(20):2170-6.

60. Naughton MP, Henderson A, Mirabelli MC, Kaiser R, Wilhelm JL, Kieszak SM, et al. Heat-related mortality during a 1999 heat wave in Chicago. Am J Prev Med. 2002;22(4):221-7.

61. Semenza JC, Rubin CH, Falter KH, Selanikio JD, Flanders WD, Howe HL, et al Heat-related deaths during the July 1995 heat wave in Chicago. N Engl J Med. 1996:335(2):84-90.

62. Anderson GB, Bell ML. Heat waves in the United States: mortality risk during heat waves and effect modification by heat wave characteristics in 43 U.S. communities. Environ Health Perspect. 2011;119(2):210-8.

63. Jenkins GJ, Murphy JM, Sexton DMH, Lowe JA, Jones PG, Kilsby C. UK Climate Projections: Briefing report. Exeter: Met Office Hadley Centre; 2009.

64. Kovats RS, Hajat S. Heat stress and public health: a critical review. Annu Rev Public Health. 2008;29:41-55.

65. Basu R, Feng WY, Ostro BD. Characterizing temperature and mortality in nine California counties. Epidemiology. 2008;19(1):138-45.

66. Vigotti MA, Muggeo VMR, Cusimano R. The effect of birthplace on heat tolerance and mortality in Milan, Italy, 1980-1989. Int J Biometeorol. 2006;50(6):335-41.

67. Huang C, Barnett AG, Wang X, Vaneckova P, Fitzgerald G, Tong S. Projecting future heat-related mortality under climate change scenarios: a systematic review. Environ Health Perspect. 2011;119(12):1681-90.

68. Knowlton K, Lynn B, Goldberg RA, Rosenzweig C, Hogrefe C, Rosenthal JK, et al. Projecting heat-related mortality impacts under a changing climate in the New York City region. Am J Public Health. 2007;97(11):2028-34.

69. Kalkstein LS, Greene JS. An evaluation of climate/mortality relationships in large U.S. cities and the possible impacts of a climate change. Environ Health Perspect. 1997;105(1):84-93.

70. Hayhoe K, Cayan D, Field CB, Frumhoff PC, Maurer EP, Miller NL, et al. Emissions pathways, climate change, and impacts on California. Proc Natl Acad Sci U S A. 2004;101(34):12422-7.

71. Gosling SN, McGregor GR, Lowe JA. Climate change and heat-related mortality in six cities Part 2: climate model evaluation and projected impacts from changes in the mean and variability of temperature with climate change. Int J Biometeorol. 2009;53(1):31-51.

72. Dessai S. Heat stress and mortality in Lisbon Part II. An assessment of the potential impacts of climate change. Int J Biometeorol. 2003:48(1):37-44.

73. Gosling SN, McGregor GR, Lowe JA. The benefits of quantifying climate model uncertainty in climate change impacts assessmemt: an example with heat-related mortality change estimates. Clim Chang. 2012;112(2):217-31.

74. Kinney PL, O'Neill MS, Bell ML, Schwartz J. Approaches for estimating effects of climate change on heat-related deaths: challenges and opportunities. In: Environmental Science \& Policy, vol. 11. Amsterdam: Elsevier; 2008. p. 87-96.

75. Hondula D, Balling RC, Vanos JK, Georgescu M. Rising temperatures, human health, and the role of adaptation. Current Climate Change Reports. 2015;1(3):144-54

76. Muthers S, Matzarakis A, Koch E. Climate change and mortality in Vienna-a human biometeorological analysis based on regional climate modeling. Int J Environ Res Public Health. 2010;7(7):2965-77.

77. Hayhoe K, Sheridan S, Kalkstein L, Greene S. Climate change, heat waves, and mortality projections for Chicago. J Great Lakes Res. 2010;36:65-73.

78. Cheng CS, Campbell M, Li Q, Li G, Auld H, Day N, et al. Differential and combined impacts of extreme temperatures and air pollution on human mortality in south-central Canada. Part II: future estimates. Air Qual Atmos Health. 2008;1(4):223-35.

79. Zhang J, Li TT, Tan JG, Huang CR, Kan HD. Impact of temperature on mortality in three major Chinese cities. Biomed Environ Sci. 2014:27(7):485-94.

80. Wu J, Zhou Y, Gao Y, Fu JS, Johnson BA, Huang C, et al. Estimation and uncertainty analysis of impacts of future heat waves on mortality in the eastern United States. Environ Health Perspect. 2014;122(1):10-6.

81. Hajat S, Vardoulakis S, Heaviside C, Eggen B. Climate change effects on human health: projections of temperature-related mortality for the UK during the 2020s, 2050s and 2080s. J Epidemiol Community Health. 2014; 68(7):641-8
82. Wilkinson P, Smith KR, Davies M, Adair H, Armstrong BG, Barrett M, et al, Public health benefits of strategies to reduce greenhouse-gas emissions: household energy. Lancet. 2009;374(9705):1917-29.

83. Heaviside C, Vardoulakis S, Cai X. Attribution of mortality to the Urban Heat Island during heatwaves in the West Midlands, UK. Environ Health. 2016; 15(Suppl 1):27.

\section{Submit your next manuscript to BioMed Central and we will help you at every step:}

- We accept pre-submission inquiries

- Our selector tool helps you to find the most relevant journal

- We provide round the clock customer support

- Convenient online submission

- Thorough peer review

- Inclusion in PubMed and all major indexing services

- Maximum visibility for your research

Submit your manuscript at www.biomedcentral.com/submit
) Biomed Central 